\title{
CANCER Risk in HIV-INFECTED INDIVIDUALS ON HAART is LARGELY AtTRibuted TO OnCOGENIC INFECTIONS AND STATE OF IMMUNOCOMPETENCE
}

\author{
M. Vogel ${ }^{1}$, O. Friedrich ${ }^{1}$, G. Lüchters ${ }^{2}$, B. Holleczek ${ }^{3}$, J. C. Wasmuth ${ }^{1}$, E. Anadol${ }^{1}$, C. Schwarze-Zander ${ }^{1}$, \\ J. Nattermann ${ }^{1}$, J. Oldenburg 4 , T. Sauerbruch 1 , J. K. Rockstroh ${ }^{1}$, U. Spengler ${ }^{1}$ \\ ${ }^{1}$ Department of Internal Medicine I. Bonn University. Bonn. Germany. \\ ${ }^{2}$ Center for Development Research (ZEF). Bonn University. Bonn. Germany. \\ ${ }^{3}$ Saarland Cancer Registry. Saarbrücken. Germany. \\ ${ }^{4}$ Institute for Experimental Hematology and Transfusion Medicine. Bonn University. Bonn. Germany
}

\begin{abstract}
Objectives: To estimate the cancer risk of HIV-infected patients in the HAART era with respect to a general reference population and to determine risk factors for malignancy.

Methods: Long term (1996-2009) cancer incidence of the Bonn single centre HIV cohort was compared to the incidence of the reference population of Saarland using standardized incidence ratios (SIR). Poisson regression analysis was used to identify predictors of cancer risk.

Results: 1,476 patients entered the cohort, enabling 8,772 person years of observation. 121 tumours in 114 patients, 7 in-situ and 114 invasive cancers, were identified. Malignancies associated with infectious agents such as Kaposi sarcoma (SIRs: male: 5,683; female: 277), non-Hodgkin lymphoma (SIRs male: 35; female: 18), anal cancer (SIRs male: 88; female: 115) as well a cervical carcinoma (SIR female: 4) and Hodgkin's disease (SIR male: 39) and liver cancer (SIR male: 18) were substantially more frequent in HIV-infected patients than in the general population ( $p<0.001$, each), whereas all other types of cancer were not increased. Poisson regression identified HAART (incidence rate ratio IRR (95\% CI): 0.28 (0.19-0.41), p<0.001), CD4 count (IRR per 100 cells $/ \mu$ increase: $0.66(0.57-0.76)$, $\mathrm{p}<0.001)$, hepatitis B (IRR: $2.15(1.10-4.20), \mathrm{p}=0.046)$ and age (IRR per 10 year increase: $1.23(1.03-1.46), \mathrm{p}$ $=0.023)$ as independent predictors for the occurrence of any type of cancer.

Conclusions: HAART and preserved CD4 cells preferentially reduce the risk of malignancies associated with oncogenic infections.
\end{abstract}

Key words: Lymphoma. Carcinoma. HIV. CD4-T cells. HAART

\section{INTRODUCTION}

Highly active antiretroviral therapy (HAART) has dramatically reduced the risk for opportunistic infections and improved overall life expectancy in patients with
HIV-infection and AIDS [1)]. However, the effects of HAART on the known increased rate of malignancies in HIV infected individuals are less clear, and due to the improved life expectancy the burden of malignancy may become more evident [2-4].

Certain types of cancer, which are rare in the general population such as Kaposi sarcoma and NonHodgkin lymphoma, are apparently linked to immunodeficiency in advanced HIV infection and have been included in the definition of AIDS [5]. In addition to AIDS defining cancers about 20 other types of malignancy, particularly those associated with oncogenic infectious agents, occur more frequently in HIV-infected patients and are probably also linked to immunodeficiency. Several studies suggest cancer incidence rates to decline under HAART but still to remain above the levels of the normal population [6-8]. However, specific HIV-associated factors potentially contributing to the risk of cancer such as current CD4 T-cell counts or co-infections with oncogenic viruses have only been taken into account by few studies todate. Such information is urgently needed to better guide initiation of antiretroviral treatment. To address this issue we assessed the incidence of cancer in a large singlecenter HIV cohort during the HAART era, and included in our analysis all types of cancer i.e. those associated with oncogenic infections as well as malignancies due to other aetiologies. Data were compared to the largest existing German cancer registry and were stratified with respect to sex, actual use of HAART, evolution of CD4 counts and co-infections to compensate for potential confounding effects.

\section{Patients And Methods}

Patients in the Bonn HIV cohort are followed on a regular basis. After informed consent has been obtained, the state of HIV infection, antiretroviral therapy, and any clinical complication including cancer and death are recorded in 3 month intervals for each patient and then entered prospectively in the local HIV data base. 
To assess the risk of cancer in the HAART era, all patients which had been entered in the Bonn HIV data base between January 1st, 1996 and December 31 st 2008 were evaluated. Data were retrieved from electronic database entries (retrolective) by means of a structured questionnaire, which comprised general demographic data, characteristics of HIV-infection, presence and details of any tumor entity (anatomical site, diagnosis date, stage and morphologic type). Malignant tumors were classified according to the anatomical site of the cancer ICD (9th edition) and tumor morphology (based on ICD-O $3^{\text {rd }}$ edition) in the case of Kaposi sarcoma (Table 1). Multiple primaries, i.e. cancers of a different type occurring in an individual with a previous diagnosis of malignant disease, were included in the analysis. Cancer incidences were calculated, excluding prevalent cases at the start of observation. In order to ensure correct capturing of newly developed cancer at the end of the observation period, data were collected until March 31 st 2009, i.e. 3 months after the end of the statistical evaluation period. Patient data were analyzed in a dynamic fashion,

Table 1. ICD9 codes used for cancer definition.

Cancer category
Kaposi sarcoma
Non-Hodgkin lymphoma
Anal cancer
230.5 - 6
Hodgkin lymphoma
Liver cancer
Cancer of the Cervix
Lung cancer
Oropharyngeal cancer
Colorectal cancer
Thyroid cancer
Cancer unknown primary
Breast
Endometrium
Melanoma
Renal

Infection-related cancer

Kaposi sarcoma. nonHodgkin lymphoma.

Hodgkin lymphoma. anal cancer. cancer of the cervix. liver cancer

ICD-9 codes
M9140\#
$200 / 202$
$154.2-154.8 ;$
201
155
$180,233.1$
$162.2-162.9$
$140-149 ; 161 ; 231.0$
$153 / 154.0-154.1 ; 231.0$
193
$199.0-199.1$
$174 ; 233.0$
$182 ; 232.2$
$189 ; 233.9$

M9140\# / 154.2 $154.8 / 155.0 / 180 /$ $200-201 / 202.0 /$ $202.8 / 230.5 / 6 /$ 233.1

Non-Infect. related cancer Lung cancer. oropharyngeal cancer. colorectal cancer. thyroid cancer. breast cancer. endometrium cancer. melanoma. renal cancer and other noninfectious related cancers

All cancer 234

\# Morphology code used alternatively as a specific ICD9 code in the 1979 edition for Kaposi sarcoma was not available i.e. the same person could contribute to different categories of risk factors depending on his/her actual classification of CD4-cell counts and other time-dependent variables at each single time point throughout the entire observation period. The population based Saarland Cancer Registry which registers invasive and in-situ malignant neoplasms since 1967 provided cancer incidence of a reference population. Completeness of case ascertainment of the Saarland Cancer Registry has been estimated to be above $95 \%[9,10]$. In order to compare the tumour incidence of the Bonn cohort with the reference population, we calculated sex and age adjusted standardized incidence ratios (SIR) and corresponding 95\% confidence intervals by tumour site and sex [11]. Observation times were classified and aggregated according to the World Health Organization conventions [11].

\section{PoIsSON REgRESSION MODEL}

An aggregated Poisson model was used to estimate incidence rate ratios (IRR) of different CD4 categories $(0-50$ cells $/ \mu \mathrm{l}, 51-100$ cells $/ \mu \mathrm{l}, 101-200$ cells $/ \mu \mathrm{l}$, $201-350$ cells $/ \mu 1,351-700$ cells $/ \mu \mathrm{l}$ and $>700$ cells $/$ $\mu \mathrm{l})$ in comparison to the reference population, adjusted for HIV-infection status and age.

In a second model we restricted the analysis to the HIV-positive Bonn cohort in order to account for additional potential confounders and to validate findings of the first model with a non-aggregated analysis. The association between CD 4 counts and cancer incidence was considered as target association, adjusted for the eligible putative confounders (sex, age, HCV co-infection, HBV co-infection, HAART, history of AIDS or CD 4 counts $<200$ cells $/ \mu \mathrm{l})$. Patients were considered to take HAAR'T within a given year if the use of three antiretroviral drugs from two different drug classes (nucleoside reverse transcriptase inhibitors, non-nucleoside reverse transcriptase inhibitors protease inhibitors, fusion or entry inhibitors or integrase inhibitors) or more than two nucleoside reverse transcriptase inhibitors had been documented for at least two consecutive 3-month observation periods. Chronic hepatitis B virus (HBV) infection was defined by the presence of Hepatitis B surface antigen, the diagnosis of chronic hepatitis $\mathrm{C}$ ( $\mathrm{HCV}$ ) virus infection required detection of $\mathrm{HCV}$ antibody in combination with HCV-RNA. To identify relevant confounders for the target association of CD4 cellcount and cancer risk exact estimates of incidence rates (IR) and incidence rate ratios (IRR) were calculated adjusted for ties and dynamic subject effects. Mantel-Haenszel adjustment was used to account for strata effects variable by variable. The model was a Poisson process with random effects using generalized estimating equations. Robustness of parameter estimates concerning malignancy of any type and of the Poisson modeling process were checked by accelerated-bias-controlled bootstrapping (5,000 replications). Statistical analysis was performed using the Stata 11.0 software package (StataCorp LP, Texas, USA) and the R programming language and software environment for statistical computing (release 2.8.0)[12]. 


\section{RESULTS}

During the 13 year observation period 1,476 patients (81\% male, $19 \%$ female) presented to our clinic. A median of 11 (range 1 - 86) medical examinations were recorded per patient resulting in a total of $24,572 \mathrm{ex}$ aminations. The total observation time was 8,772 person years of follow-up. Demographic characteristics are summarized in Table 2.

During the observation period 121 tumors (114 invasive, 7 in-situ) were observed in 114 patients. Seven patients suffered from a second malignancy. The annual rate of cancer incidence (1908/100,000 person years) did not change over the observation period. Comparing the cancer incidence rates in the Bonn cohort with the general population of Saarland, more malignancies were observed among HIV-positive patients of the Bonn cohort (Table 3). However, conspicuous differences in the standardized incidence ratio (SIR) were revealed, when the observed tumors were classified into infection-related types and cancer unrelated to infectious diseases: Whereas cancers occurring

Table 2. Baseline characteristics of the Bonn cohort at the start of observation.

\begin{tabular}{|c|c|}
\hline & $\begin{array}{c}\text { Bonn cohort } \\
n=1476\end{array}$ \\
\hline Age [yrs] & $36(16-85)$ \\
\hline Male sex $[\%]$ & 81 \\
\hline $\begin{array}{l}\text { Race }[\%] \\
\text { Caucasian } \\
\text { Afro-american } \\
\text { Asian } \\
\text { Hispanic } \\
\text { other / unknown }\end{array}$ & $\begin{array}{l}85 \\
11 \\
2 \\
1 \\
1\end{array}$ \\
\hline $\begin{array}{l}\text { Transmission-Risk [\%] } \\
\text { homosexual } \\
\text { heterosexual } \\
\text { endemic } \\
\text { blood products } \\
\text { i.v. drug abuse } \\
\text { unknown }\end{array}$ & $\begin{array}{c}47 \\
14 \\
12 \\
11 \\
10 \\
5\end{array}$ \\
\hline $\begin{array}{l}\text { Hepatitis Coinfection [\%] } \\
\text { HBV } \\
\text { HCV }\end{array}$ & $\begin{array}{c}4 \\
21\end{array}$ \\
\hline AIDS or CD $4<200 / \mu 1[\%]$ & 35 \\
\hline $\begin{array}{l}\text { HAART [\%] } \\
3 \times / 4 x \text { NRTI } \\
\text { NNRTI } \\
\text { PI } \\
\text { Salvage }\end{array}$ & $\begin{array}{c}40 \\
6 \\
25 \\
65 \\
3\end{array}$ \\
\hline CD4-cells $[/ \mu \mathrm{l}]$ & 359 \\
\hline HIV-RNA [log10] & 3.9 \\
\hline
\end{tabular}

Continuous variables are given as median (range). categorical variables as percent of patients ( $95 \%$ confidence interval). Abbreviations: i.v. intravenous; HBV hepatitis B infection; HCV hepatitis C infection; AIDS acquired immunodeficiency syndrome; HAART highly active antiretroviral therapy. as a complication of human herpes virus 8 (Kaposi sarcoma), Epstein Barr virus (non-Hodgkin lymphoma and Hodgkin's disease), hepatitis B and C viruses (hepatocellular carcinoma) and human papilloma virus (anal carcinoma and carcinoma of the cervix) were observed significantly more frequently among HIV-positive patients $(p<0.001$ each), cancers unrelated to infectious disesase occurred at similar rates as in the reference population.. The incidence of cancer entities unrelated to infectious diseases was apparently not correlated to the degree of immunodeficiency (Fig. 1c). In contrast, incidence rate ratios of infection-related cancers were closely correlated to the degree of immunodeficiency as reflected by CD4 counts $(p<0.001$ for trend, Fig. 1b). The cancer risk increased the more the lower CD4-cell counts had dropped below $350 / \mu \mathrm{l}$ (Fig. 1a). Of note, however, the risk for cancer remained above the level of the reference population for all CD4 strata. To take into account the potential contribution from confounding parameters we first performed univariate comparisons to identify putative confounding variables to be further explored in a multivariate regression model. We investigated whether sex, age or HCV co-infection were associated with CD4 cell-count as the putative cause and the occurrence of cancer as the effect and found that none of these potential confounders, interfered with both the putative cause "CD4 cell-count" and the effect "cancer". In contrast, "history of AIDS" or "history of a CD4 cell-count below $200 / \mu l$ ", "HBV co-infection" and "use of HAART" were strongly associated with

a)

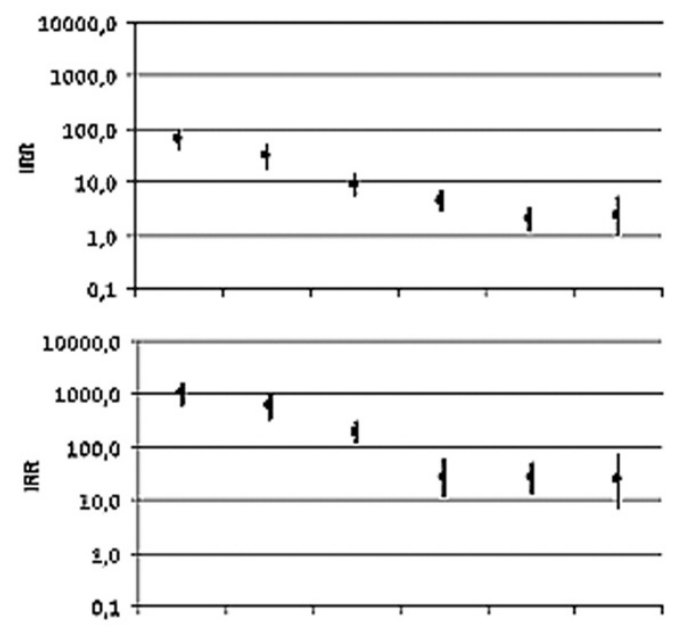

c)

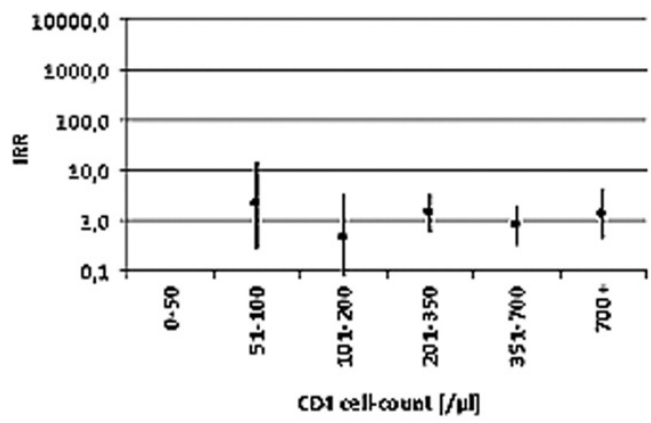

Fig. 1a-c. Incidence rate ratios male patients, stratified according to HIV- and CD4-status: a) all cancer, b) infection related, c) cancer unrelated to infectious diseases. 
Table 3. Cancer incidence. standardized incidence ratios (SIR) and corresponding $95 \%$ confidence intervals by primary site and sex

\begin{tabular}{|c|c|c|c|c|c|}
\hline Sex & Malignancy & $\begin{array}{l}\text { Observed Events } \\
\text { Bonn cohort } \\
1996-2008 \\
\text { n }\end{array}$ & $\begin{array}{l}\text { Expected } \\
\text { Events* }\end{array}$ & SIR $(95 \% \mathrm{CI})$ & p-Value \\
\hline \multirow[t]{15}{*}{ Male } & Kaposi & 41 & $<0.1$ & $5682.6(4076.3-7555.2)$ & $<0.001$ \\
\hline & NHL & 28 & 0.8 & $35.0(23.3-49.2)$ & $<0.001$ \\
\hline & Hodgkin & 8 & 0.2 & $38.7(16.5-70.2)$ & $<0.001$ \\
\hline & Liver & 7 & 0.4 & $18.2(7.2-34.1)$ & $<0.001$ \\
\hline & Anal & 6 & 0.1 & $87.8(31.6-172.1)$ & $<0.001$ \\
\hline & Lung & 5 & 3.3 & $1.5(0.5-3.1)$ & 0.509 \\
\hline & Oropharyngeal & 3 & 2.4 & $1.1(0.2-2.7)$ & 0.905 \\
\hline & Colorectal & 3 & 2.7 & $1.1(0.2-2.8)$ & 0.920 \\
\hline & CUP & 2 & 0.6 & $3.5(0.3-10.1)$ & 0.215 \\
\hline & Melanoma & 1 & 2.1 & $0.5(0.0-1.9)$ & 0.682 \\
\hline & Thyroid & 1 & 0.2 & $5.2(0.0-20.6)$ & 0.478 \\
\hline & Renal & 1 & 0.9 & $1.1(0.0-4.3)$ & 0.660 \\
\hline & All cancer & 106 & 24.1 & $4.4(3.6-5.3)$ & $<0.001$ \\
\hline & Infection-related & 89 & 1.2 & $75.5(60.6-92.0)$ & $<0.001$ \\
\hline & Non-Infect. related & 17 & 21.6 & $0.8(0.5-1.2)$ & 0.374 \\
\hline \multirow[t]{10}{*}{ Female } & Cervix & 6 & 1.5 & $4.0(1.5-7.9)$ & 0.001 \\
\hline & Kaposi & 2 & $<0.1$ & $277.2(26.1-794.5)$ & $<0.001$ \\
\hline & NHL & 2 & 0.1 & $18.2(1.7-52.1)$ & $<0.001$ \\
\hline & Anal & 2 & $<0.1$ & $115.2(10.9-330.1)$ & $<0.001$ \\
\hline & Breast & 1 & 1.5 & $0.7(0.0-2.6)$ & 1.000 \\
\hline & Endometrium & 1 & 0.2 & $5.3(0.0-20.9)$ & 0.472 \\
\hline & Thyroid & 1 & 0.1 & $8.0(0.0-31.4)$ & 0.289 \\
\hline & All cancer & 15 & 6.0 & $2.5(1.4-3.9)$ & $<0.001$ \\
\hline & Infection-related & 12 & 1.6 & $7.3(3.8-12.0)$ & $<0.001$ \\
\hline & Non-Infect. related & 3 & 4.1 & $0.7(0.1-1.8)$ & 0.780 \\
\hline
\end{tabular}

* Expected events within the Bonn cohort based on the age-specific rates of the Saarland population (11).

CD4 cell-count and occurrence of cancer (Table 4).

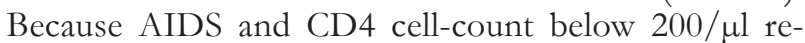
flect the natural course of HIV infection this parameter was not considered within the multivariate model. HAART on the other hand is known to counteract the natural course of HIV-infection and was thus included in the model. After adjustment for potential confounders a significant influence of the current CD4 cell-count on the risk for cancer remained. Per 100 CD4-cell increase the incidence rate decreased by $34 \%$ (IRR $0.66,95 \%$ CI $0.56-0.78, \mathrm{p}<0.001$ ) and $46 \%$ (IRR $0.54,95 \%$ CI $0.46-0.65$ ) for all types of cancer and infection-related cancers, respectively. Inclusion of "history of AIDS" or "CD4 cell-count below 200/ $\mu$ l" did not change the significant impact of current CD4 cell-count on the risk for cancer or infection-related cancer (IRR 0.74, 95\% CI $0.64-0.85$ and IRR 0.62, $95 \%$ CI $0.52-0.74$ respectively). HBV co-infection, age and use of HAART independently increased and decreased the cancer risk, respectively (Table 5). The protective effect of HAART was most pronounced in infection-related types of cancer, where HAART reduced the risk for cancer by $76 \%$. In contrast, while the risk for cancer unrelated to infectious diseases appear to be not affected by current CD 4 cell-counts, use of HAART may also slightly attenuate the cancer risk for these cancer entities (decrease by $48 \%$ (IRR 0.42, $95 \%$ CI $0.17-1.06, \mathrm{p}=0.065)$.

\section{DisCUSSION}

In the Bonn HIV cohort individuals had a significantly higher risk for cancer as compared to the normal population with an overall standardized incidence ratio of 4 for women and 6 for men. The cancer risk varied considerable depending on the type of cancer. Cancers with an underlying infectious pathogen occurred roughly 30 (female) - 100 (male) times more frequently among HIV-positive individuals compared to the normal population (Table 3). On the contrary, cancer types unrelated to infectious diseases were found at a similar rate as in the normal population. The observed incidence rates of cancer in the Bonn HIV cohort were well within the range of data reported recently from large US-American and French AIDS and tumor registries [7, 13]. However, the observed rate for Kaposi 
Table 4. Confounder identification.

\begin{tabular}{|c|c|c|c|}
\hline & $\begin{array}{c}\text { CD4-cells } \\
\mathbf{0 - 5 0} \\
\mathrm{n}=164\end{array}$ & $\begin{array}{c}\text { CD4-cells } \\
\mathbf{5 0 +} \\
\mathrm{n}=1.312\end{array}$ & $\begin{array}{c}\text { Univariate } \\
\text { p-value }\end{array}$ \\
\hline Male sex $[\%]$ & 79 & 81 & 0.602 \\
\hline Age [years] & $36(19-77)$ & $36(16-85)$ & 0.316 \\
\hline $\mathrm{HCV}[\%]$ & 16 & 21 & 0.124 \\
\hline AIDS or CD $4<200 / \mu 1[\%]$ & 91 & 33 & $<0.001$ \\
\hline $\mathrm{HBV}[\%]$ & 7 & 4 & 0.056 \\
\hline HAART [\%] & 62 & 42 & $<0.001$ \\
\hline $3 \mathrm{x} / 4 \mathrm{x}$ NRTI & 5 & 7 & 0.327 \\
\hline NNRTI & 19 & 26 & \\
\hline PI & 75 & 64 & \\
\hline \multirow[t]{2}{*}{ Salvage } & 1 & 4 & \\
\hline & $\begin{array}{l}\text { Cancer } \\
\mathrm{n}=114\end{array}$ & $\begin{array}{c}\text { No cancer } \\
\mathrm{n}=1.362\end{array}$ & $\begin{array}{c}\text { Univariate } \\
\mathrm{p} \text {-value }\end{array}$ \\
\hline Male sex $[\%]$ & 88 & 80 & 0.048 \\
\hline Age [years] & $39(19-69)$ & $36(16-85)$ & 0.004 \\
\hline $\mathrm{HCV}[\%]$ & 18 & 21 & 0.404 \\
\hline AIDS or CD $4<200 / \mu 1[\%]$ & 62 & 33 & $<0.001$ \\
\hline $\mathrm{HBV}[\%]$ & 9 & 4 & 0.011 \\
\hline HAART [\%] & 32 & 45 & 0.006 \\
\hline $3 \mathrm{x} / 4 \mathrm{x}$ NRTI & 0 & 7 & 0.255 \\
\hline NNRTI & 18 & 25 & \\
\hline PI & 65 & 65 & \\
\hline Salvage & 6 & 3 & \\
\hline
\end{tabular}

Data shown as median (range) or percent where applicable. All comparisons refer to the time of first observation. Fisher's exact test or two-sample t-test were used for statistical comparison.

Table 5. Effect of current CD4 cell-count on the incidence of cancer. adjusted for presumed eligible confounders.

\begin{tabular}{|c|c|c|c|c|}
\hline & Parameter & IRR & $95 \% \mathrm{CI}$ & $\mathrm{p}$-value \\
\hline \multirow{4}{*}{ All cancer } & CD4 [per 100 cells $/ \mu l]$ & 0.66 & $0.57-0.76$ & $<0.001$ \\
\hline & HBV co-infection & 2.15 & $1.10-4.20$ & 0.024 \\
\hline & Use of HAART & 0.28 & $0.19-0.41$ & $<0.001$ \\
\hline & Age [per 10 years] & 1.23 & $1.03-1.46$ & 0.023 \\
\hline \multirow[t]{4}{*}{ Infectious related cancer } & CD4 [per 100 cells $/ \mu \mathrm{l}]$ & 0.54 & $0.46-0.65$ & $<0.001$ \\
\hline & HBV co-infection & 1.99 & $1.02-3.90$ & 0.045 \\
\hline & Use of HAART & 0.24 & $0.16-0.37$ & $<0.001$ \\
\hline & Age [per 10 years] & 1.10 & $0.91-1.34$ & 0.334 \\
\hline \multirow[t]{4}{*}{ Non-infectious related cancer } & CD4 [per 100 cells $/ \mu \mathrm{l}]$ & 1.11 & $0.97-1.26$ & 0.125 \\
\hline & HBV co-infection & 3.08 & $0.73-13.1$ & 0.129 \\
\hline & Use of HAART & 0.42 & $0.17-1.06$ & 0.065 \\
\hline & Age [per 10 years] & 1.99 & $1.52-2.61$ & $<0.001$ \\
\hline
\end{tabular}

IRR incidence rate ratio; CI confidence interval

sarcoma in the Bonn cohort was higher (651 95\% CI 457 - 845 per 100.000 person-years) than that reported by Guiguet et al. (232, 95\% CI 213 - 251) but lower than that reported by Patel et al. (1252, 95\% CI $1196-$ 1309). Likewise, the incidence rates of non-Hodgkin lymphoma (454, 95\% CI 292 - 617 vs. 209 , 95\% CI $192-228)$ and carcinoma of the cervix $(475,95 \%$ CI 177 - 1030 vs. 93 95\% CI 71 - 115) were higher in our cohort than in the French cohort [13].The different rates of Kaposi sarcoma most likely reflect differences 
in the study populations and in observation period. Whereas $32 \%$ of patients in the French cohort were men who had sex with men (MSM), in our cohort $47 \%$ of patients were MSM, which carry an increased risk to develop Kaposi sarcoma as compared to female patients and other HIV-positive patients with different transmission risks [13-15]. Moreover, our observation time was confined to the HAART era, while Patel. and colleagues had investigated a larger time-span encompassing both the pre-HAART and HAART era. When comparing the incidence rates confined to the HAART era, the rates of Kaposi sarcoma were comparable between both studies, since incidence rates of Kaposi sarcoma decreased after the introduction of HAART [7]. Likewise, different rates of non-Hodgkin lymphoma, seem to reflect differences in the gender proportions and risk factors of transmission [13]. On the other hand the difference in the rates for cancer of the cervix has to be attributed to the fact that unlike the French cohort we had also included carcinoma in-situ, since incidence rates for invasive cancer of the cervix were rather similar between the French and Bonn cohort (SIR 1.58, 95\% CI 0.18 - 5.68, Table 3).

The risk for cancer was particular pronounced for tumor entities related to infectious diseases which are probably particularly affected by immunodeficiency [16]. Though the risk for cancer in this category was increased regardless of CD4 cell-count, the cancer risk further increased gradually when CD4-cell counts dropped below normal and was highest among patients with CD4-cell counts below 50 cells/ $\mu$ l. However, the sample size and length of observation period were not sufficient to distinguish differences in the CD4 threshold for the increase in risk of distinct cancer types.

Unlike our study Guiguet et al. also reported a significant impact of CD4-cell counts on the risk of lung cancer [13], which was approximately ten-fold increased in patients with CD4 cell-counts $<50 / \mu \mathrm{l}$. Although the crude incidence of lung cancer had the same order of magnitude in both studies (57.0 vs 81.1 per 100,000 person years), the number of our patients may have been too small as to reveal this effect. Similarly, in contrast to previous studies [17] our study did not find an increased risk for thyroid cancer, endometrial cancer and CUP, which may be attributable to the small numbers of these tumor types in our cohort.

HAART attenuated the cancer risk independently from CD4 cell-counts in line with previous observations $[13,18,19]$. Nevertheless, the threshold when to start HAART to reduce the risk of malignancy is less clear. Current guidelines of the European AIDS Clinical Society recommend HAART in the absence of additional risk factors if CD4-cell counts drop below 350 cells $/ \mu$ l, [20]. In contrast, US-American guidelines recommend HAART at a thresholf of 500 CD4 cells $/ \mu$, although the panel was divided whether to make this a strong or moderate recommendation [21]. Considering tumor risk as a factor for HAART indication, our data suggest only little increase for CD4 cellcounts above $350 / \mu$ land thus would rather favour the European recommendations. However, it has to be taken into account that for some tumors important pathogenetic steps may occur at early stages, if not immediately after HIV-infection, when large amounts of the immune-repertoire are lost rapidly within the first few days of HIV infection [22]. Of note, we reported an increased risk for all types of cancer and infection-related cancer in patients with chronic HBV infection. We assume that HBV- infection in patients with non-infectious types of cancer might have been a surrogate marker for a certain life style. Among the 16 cancer patients with chronic hepatitis B, five patients developed Kaposi sarcoma; 2 developed NHL, 2 HCC, 3 anal carcinoma, and 3 patients suffered from oropharyngeal cancer. Thus, also in the case of infection-associated types of cancers, HCC only was the ultimate tumor only in few patients. Otherwise, 8 of the patients with hepatitis B had homosexual contacts, which is a risk factor for KS and anal carcinoma suggesting a life style related causality.

\section{CONCLUSIONS}

The risk of cancer in the setting of HIV-infection is reduced by antiretroviral therapy but remains above that of the HIV-uninfected reference population in the case of tumor entities with an underlying infectious etiology irrespective if these tumors have been classified as AIDS-defining or not. In the subgroup with infection-related malignancies the tumor risk is clearly correlated to the degree of immunodeficiency at the time of tumor appearance, whereas tumors without an underlying infectious cause occurred at a similar frequency as in the reference population and did not show a clear relationship to CD4 counts. Further large studies are justified to define the optimum CD4 threshold for start of HAART in order to reduce the risk for distinct infection-related malignancies.

Acknowledgements: We kindly thank Caroline Sabin, University College of London, United Kingdom. for technical notes to refine our statistical model.

\section{REFERENCES}

1. Mocroft A, Ledergerber B, Katlama C, et al. Decline in the AIDS and death rates in the EuroSIDA study: an observational study. Lancet. 2003; 362:22-9.

2. Friis-Moller N, Sabin CA, Weber R, et al. Combination antiretroviral therapy and the risk of myocardial infarction. N Engl J Med. 2003; 349:1993-2003.

3. Goulet JL, Fultz SL, Rimland D, et al. Aging and infectious diseases: do patterns of comorbidity vary by HIV status, age, and HIV severity? Clin Infect Dis. 2007; 45:1593-601.

4. Rosenthal E, Pialoux G, Bernard N, et al. Liver-related mortality in human-immunodeficiency-virus-infected patients between 1995 and 2003 in the French GERMIVIC Joint Study Group Network (MORTAVIC 2003 Study). J Viral Hepat. 2007; 14:183-8.

5. Castro K, Ward J, Slutsker L, Buehler J, Jaffe H and Berkelman R. 1993 Revised Classification System for HIV Infection and Expanded Surveillance Case Definition for AIDS among Adolescents and Adults. Morbidity and Mortality Weekly Report. 1992; 41:1.

6. Engels EA, Pfeiffer RM, Goedert JJ, et al. Trends in cancer risk among people with AIDS in the United States 1980-2002. AIDS. 2006; 20:1645-54. 
7. Patel P, Hanson DL, Sullivan PS, et al. Incidence of types of cancer among HIV-infected persons compared with the general population in the United States, 1992-2003. Ann Intern Med. 2008; 148:728-36.

8. Shiels MS, Cole SR, Kirk GD and Poole C. A MetaAnalysis of the Incidence of Non-AIDS Cancers in HIVInfected Individuals. J Acquir Immune Defic Syndr. 2009.

9. Katalinic A, Bertz J, Haberland J and Wolf U. Cancer in Germany 2003-2004. Incidence and Trends. Berlin: Association of Population-based Cancer Registries in Germany and Robert Koch Institute; 2008.

10. Haberland J, Bertz J, Gorsch B and Schon D. [Cancer incidence estimates for Germany via log-linear models]. Gesundheitswesen. 2001; 63:556-60.

11. Boyle P and Parkin D. Cancer registration: principles and methods. Statistical methods for registries. IARC Sci Publ. 1991; 95:126-58.

12. R Development Core Team. R: A Language and Environment for Statistical Computing. Vienna: R Foundation for Statistical Computing; 2009.

13. Guiguet M, Boue F, Cadranel J, Lang JM, Rosenthal E and Costagliola D. Effect of immunodeficiency, HIV viral load, and antiretroviral therapy on the risk of individual malignancies (FHDH-ANRS CO4): a prospective cohort study. Lancet Oncol. 2009.

14. Albrecht H, Helm EB, Plettenberg A, et al. Kaposi's sarcoma in HIV infected women in Germany: more evidence for sexual transmission. A report of 10 cases and review of the literature. Genitourin Med. 1994; 70:394-8.

15. Laney AS, Cannon MJ, Jaffe HW, et al. Human herpesvirus 8 presence and viral load are associated with the progression of AIDS-associated Kaposi's sarcoma. AIDS. 2007; 21:1541-5.

16. Grulich AE, van Leeuwen MT, Falster MO and Vajdic CM. Incidence of cancers in people with HIV/AIDS compared with immunosuppressed transplant recipients: a meta-analysis. Lancet. 2007; 370:59-67.

17. Powles T, Robinson D, Stebbing J, et al. Highly active antiretroviral therapy and the incidence of non-AIDS-defining cancers in people with HIV infection. J Clin Oncol. 2009; 27:884-90.
18. Bruyand M, Thiebaut R, Lawson-Ayayi S, et al. Role of uncontrolled HIV RNA level and immunodeficiency in the occurrence of malignancy in HIV-infected patients during the combination antiretroviral therapy era: Agence Nationale de Recherche sur le Sida (ANRS) CO3 Aquitaine Cohort. Clin Infect Dis. 2009; 49:1109-16.

19. Clifford GM, Polesel J, Rickenbach M, et al. Cancer risk in the Swiss HIV Cohort Study: associations with immunodeficiency, smoking, and highly active antiretroviral therapy. J Natl Cancer Inst. 2005; 97:425-32.

20. Clumeck N, Pozniak A, Raffi F and EACS Executive Committee. Guidelines on the Clinical Management and Treatment of HIV Infected Adults in Europe. EACS European AIDS Clinical Society. Paris, France: available online at www.europeanaidsclinicalsociety.org/guidelines.asp, accessed December 8th, 2009.

21. Panel on Antiretroviral Guidelines for Adults and Adolescents. Guidelines for the use of antiretroviral agents in HIV-1-infected adults and adolescents. Department of Health and Human Services.December 1, 2009; 1 - 161. Available at www.aidsinfo.nih.gov/ContentFiles/AdultandAdoles centGL.pdf, accessed December 8th, .

22. Lackner AA, Mohan M and Veazey RS. The gastrointestinal tract and AIDS pathogenesis. Gastroenterology. 2009; 136:1965-78.

Received: December 10, 2010 / Accepted: December 22, 2010

Address for correspondence:

Prof. Dr. med. U. Spengler.

Department of Internal Medicine I

Bonn University

Sigmund-Freud-Str. 25

53105 Bonn

Email: ulrich.spengler@ukb.uni-bonn.de 